\title{
BMJ Open Assessing the exposure of street sweeping and potential risk factors for developing musculoskeletal disorders and related disabilities: a cross-sectional study
}

\author{
Pradeep S Salve, Praveen Chokhandre
}

To cite: Salve PS, Chokhandre P. Assessing the exposure of street sweeping and potential risk factors for developing musculoskeletal disorders and related disabilities: a cross-sectional study. BMJ Open 2016;6:e012354. doi:10.1136/bmjopen-2016012354

- Prepublication history for this paper is available online. To view these files please visit the journal online (http://dx.doi.org/10.1136/ bmjopen-2016-012354).

Received 20 April 2016 Revised 1 November 2016 Accepted 28 November 2016

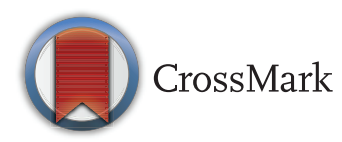

International Institute for Population Sciences, Mumbai, Maharashtra, India

Correspondence to Praveen Chokhandre; praveenchokhandre@gmail. com

\section{ABSTRACT}

Objective: This study aims to assess the exposure of those involved in street sweeping to the development of musculoskeletal disorders (MSDs) and related disabilities and tries to identify the individual risk factors thereof.

Design: A cross-sectional survey was conducted among street sweepers together with a comparison group. A modified Standardized Nordic Questionnaire was adopted to measure the prevalence of MSDs and related disabilities. The impact of the occupation of sweeping on the development of MSDs and related disabilities was assessed using the propensity score matching (PSM) method. A multivariate logistic regression model was employed to identify the individual risk factors.

Participants: Street sweepers $(n=180)$ and a comparison group $(n=180)$, working for at least a year as formal employees of the Municipal Corporation of Greater Mumbai (MCGM), were randomly selected from 6 municipal wards.

Results: The prevalence of the MSDs was significantly higher among the sweepers for shoulders (32\%), wrists/hands (29\%), elbows ( $27 \%$ ) and neck (17\%) compared with the comparison group, in which the prevalence was $11 \%, 19 \%, 9 \%$ and $11 \%$, respectively. The disabilities too were significantly higher among the street sweepers for the lower back (27\%), upper back $(27 \%)$, wrists/hands $(26 \%)$, shoulders $(24 \%)$ and elbows (23\%) compared with the comparison group, for which the figures were $18 \%, 19 \%, 13 \%, 9 \%$ and $6 \%$ respectively. The PSM method highlighted that the occupation of sweeping raised the risk of developing MSDs and disabilities particularly for the shoulders (17-16\%), wrists/hands (14\% each), elbows (13\% each) and the upper back (12-13\%). After adjusting the age, body mass index and the caste of the street sweepers, the number of years of engagement in street sweeping and the location of work emerged as potential risk factors in the development of MSDs and, thereby, related disabilities.

Conclusions: The study concluded that the occupation of street sweeping raises the risk of MSDs and related disabilities. This study recommends

\section{Strengths and limitations of this study}

- The present study assessed musculoskeletal disorders (MSDs) and MSD-related disabilities among street sweepers, whereas past studies have primarily focused on the occupational morbidities other than MSDs among street sweepers.

- The propensity score matching method was adopted to assess the exposure of street sweeping on the development of MSDs and related disabilities.

- Bias in recalling MSDs and disabilities is possible due to the reference period being 1 year long.

- The participants of the study carried out sweeping manually; hence, the results may be generalised with caution.

preventive and curative measures to deal with MSDs among street sweepers.

\section{INTRODUCTION}

The occupation of sweeping is a vigorous task that involves sweeping of assigned areas such as roads, footpaths, parks, markets and open settlements with the help of long-handle brooms and wheelbarrows and deposition of the waste in nearby community dustbins. This whole process requires continuous physical tasks such as manually sweeping in the standing posture for long durations, bending while collecting the swept waste, pushing and pulling the wheelbarrow, and manually lifting the baskets to deposit waste. A similar process is followed in other cities in India and other developing countries. The Municipal Corporation of Greater Mumbai (MCGM) has 9231 regular employees engaged in the 
street sweeping occupation, and the corresponding figure must be many times higher for India as a whole. Numerous studies have concluded that the occupational exposure of sweeping is associated with the development of chronic respiratory diseases, skin diseases, eye irritation, asthma, tuberculosis and hypertension among workers. ${ }^{1-4}$ The other non-fatal injuries identified are mostly musculoskeletal in nature. Musculoskeletal disorders (MSDs) are defined as pain, ache or discomfort in any of the anatomical areas of the body, namely neck, shoulders, upper back, lower back, elbows, wrists or hands, hips or thighs, knees, and ankles or feet. ${ }^{5}$

Past studies conducted among solid waste collectors suggest a higher probability among them of developing MSDs compared with the general population. ${ }^{5-7}$ Workers involved in repetitious physical tasks by bending, lifting, pushing and pulling for long durations have been identified as facing the risk of developing MSDs. ${ }^{8-10}$ So far, very few studies have been conducted among street sweepers and hardly any study has thoroughly assessed the risk of MSDs among street sweepers. Past studies conducted among street sweepers have predominantly focused on eye, skin and respiratory morbidities in India. ${ }^{41-14}$ The present study, in contrast, aimed to assess the occupational exposure of sweeping to the development of MSDs as well as disabilities. Additionally, the study tried to identify the individual risk factors leading to the development of MSDs and disabilities among street sweepers.

\section{MATERIALS AND METHODS}

\section{Study design and participants}

The study applied a cross-sectional design to assess the prevalence of MSDs and related disabilities among street sweepers compared with a comparison group. A street sweeper sweeps assigned areas-such as roads, residential areas, markets, public parks and open settlementsusing a long-handle broom and a wheelbarrow to deposit the collected waste in nearby community dustbins. Sweepers work 8 hours daily in pairs. A group of municipal workers not exposed to sweeping-including employees associated with fogging and pesticide spraying and peons having similar socioeconomic conditions-were selected as the comparison group. These employees were basically field workers of the MCGM, working continuously in the field, performing heavy physical tasks such as carrying necessary equipment/machines. Their work load was more or less similar to that of the sweepers.

The present study was primarily conducted to examine the major morbidities, including MSDs, among municipal street sweepers. The estimated sample size was 180 with a prevalence rate of 30 and a design effect of 1.25. ${ }^{11}$ Applying stratified systematic random sampling design, the required sample was collected randomly from 6 out of 24 municipal wards of the MCGM based on the proportion of the slum population to the total population. At the first stage, all 24 municipal wards were arranged in the ascending order of their slum population and divided into three strata, that is, low, moderate and high. At the second stage, two wards were randomly selected from each stratum. Based on the list of employees provided by the Municipal Corporation, a representative sample of 60 employees from each ward (ie, 30 sweepers and 30 non-sweepers) was selected through systematic random sampling. Finally, a sample of 180 street sweepers and 180 non-sweepers were interviewed at the workplace from March to September 2015.

\section{Measurements}

A modified Standardized Nordic Questionnaire was adopted to assess the MSDs. ${ }^{15}$ A diagram, with labels and arrows clearly indicating the different musculoskeletal regions, was used for the assessment of MSDs during the 12 months and the 7 days preceding the survey. The interview schedule collected information on the MSDs along with demographic, socioeconomic and occupational characteristics. Specifically, the schedule covered age, years of work, substance use, anthropometric measurements, job satisfaction, caste and mental health.

\section{Variables}

\section{Outcome variables}

The respondents who reported pain in nine anatomical regions-namely neck, shoulders, elbows, wrists/hands, upper back, lower back, hips/thighs, knees and anklesduring the 7 days and 12 months prior to the survey were considered to be morbid with MSDs. The sweepers who were prevented from doing normal day-to-day activities at home or away from home due to the MSDs in the preceding 12 months were classified and recoded as disabled.

\section{Exposure classification}

Age and years of working are significant predictors of development of MSDs among solid waste collectors, with the risk of MSDs increasing with increasing age and years of working. ${ }^{5}$ Past studies have concluded that overweight and obesity are positively associated with MSDs because of the pressure exerted on the weight-bearing joints. ${ }^{16} 17$ Symptoms of worry, tension, anxiety, work stress and low mood too have a correlation with musculoskeletal pain. ${ }^{18-20}$ The prevalence of MSDs and disabilities can vary between groups of workers sharing different cultural characteristics ${ }^{21}$ therefore, caste of the workers was also considered.

Job satisfaction of employees also influences the prevalence of MSDs. ${ }^{22}$ Job satisfaction is measured on a scale of $1-5$, with 1 being very bad and 5 being very good. In the present study, the responses were scored as 1, 2, 3 in place of being measured using the Likert scale of 1-5 to eliminate any biases which might result from the respondents choosing responses 1 and 2 or 4 and 5, respectively. Finally, the responses were recoded as low, medium and high. Past studies show that psychosocial factors, 
such as mental health and job satisfaction, may increase or decrease the prevalence of MSDs among the street sweepers too. ${ }^{21}$

The quantum of work that sweepers have to do in low or high slum concentration areas too may affect the prevalence of MSDs and related disabilities among them. Since sweeping in the slum areas is a more rigorous task due to unorganised garbage disposal, overflowing community dustbins and defaecation by the children on the footpaths, the workload can be higher. Therefore, the location of work was considered to be one of the risk factors. Based on the proportion of the slum population to the total population, the wards were divided into three categories, that is, low, moderate and high. Job satisfaction, location of work and mental health of sweepers were considered to be effect modifiers.

The mental health of sweepers was analysed by applying the General Health Questionnaire of 12 items (GHQ-12). ${ }^{23}$ The workers were asked whether they had experienced any positive or negative emotions in the previous month. Each negative response was coded 1, while the absence of it was coded 0 . The items were summed to a score for each respondent. The higher the score was from 0 to 12 , the more severe the mental health problem was considered to be. Further, the score was divided into three categories, namely low, medium and high. The mental health scale has acceptable internal consistency $(\alpha=0.97) .^{24}$

\section{Statistical analysis}

The data were entered in the CSPro.06 software and analysed using the STATA V.13 (StataCorp. Stata Satistical Software: Release 14. 2015) software. Descriptive statistics were used to understand the socioeconomic and occupational characteristics. Differences in the prevalence of MSDs and the related disabilities were tested using the $\chi^{2}$ test. The differences in groups were tested using independent sample t-test.

While assessing the exposure of the occupation of sweeping to the development of MSDs, the study adopted the nearest neighbourhood method of propensity score matching (PSM). ${ }^{25}{ }^{26}$ The method allowed assessment of the impact of exposure on the outcomes using cross-sectional survey data. The propensity score was estimated with the logistic regression analysis with the dichotomous exposure variable, for instance $1=$ exposed to sweeping and $0=$ unexposed to sweeping, using associated observed demographic and occupational characteristics and used as predictor variables. The principal assumption of the PSM is that the observable characteristics of the exposed and the comparison groups have similar distributions. This assumption test was applied by using the 'p score' command. The propensity score was calculated using the probability of exposure assignment given pre-exposure characteristics.

$$
\mathrm{p}(\mathrm{x}) \equiv \operatorname{prob}(\mathrm{D}=1 \mid \mathrm{xi})=\mathrm{E}(\mathrm{D} \mid \mathrm{xi})
$$

where $\mathrm{D}=\{0,1\}$ is the indicator of exposure and $\mathrm{x}$ is the multidimensional vector of pre-exposure characteristics.

The average exposure effect among the exposed (AEEE) is defined as the conditional expectation of difference in the exposure effect for the exposed units only. After matching the propensity scores of exposed and counterfactual scores of comparison group, we compared the outcomes between the groups.

$$
\begin{aligned}
\text { AEEE }=\mathrm{E}(\Delta \mid \mathrm{p}(\mathrm{x}), \mathrm{D}=1) & =\mathrm{E}\left(\mathrm{y}_{1} \mid \mathrm{p}(\mathrm{x}), \mathrm{D}=1\right) \\
& -\mathrm{E}\left(\mathrm{y}_{0} \mid \mathrm{p}(\mathrm{x}), \mathrm{D}=1\right)
\end{aligned}
$$

To calculate the impact of street sweeping on the development of MSDs and related disabilities during the previous 12 months, the average effects in both the groups were weighted by the proportion of respondents in the two groups. Further, to understand the individual risk factors for MSDs and disabilities among sweepers, multiple logistic regression analysis was applied.

\section{Ethical considerations}

As the study involved government employees, permission to conduct the primary survey was obtained from the MCGM. The informed consent of the participants was obtained in the local language, and the respondents were assured that the information would be confidential and used for research purposes only.

\section{RESULTS}

\section{Characteristics of the study population}

The socioeconomic and occupational characteristics of the street sweepers and the comparison group have been depicted in table 1 . There was a small difference in the mean age of the street sweepers ( 37 years, $\mathrm{SD} \pm 9.12$ ) and that of the comparison group (38 years, $\mathrm{SD} \pm 7.39)$. A similar pattern was observed while looking at the years of working of the street sweepers (11 years, $\mathrm{SD} \pm 8.30$ ) and those of the comparison group (11 years, $\mathrm{SD} \pm 6.35)$. Substance use, such as alcohol consumption, smoking and chewing tobacco, was higher among the sweepers compared with the comparison group. For instance, nearly $70 \%$ of the sweepers reported using at least one type of substance. A little less than one-third reported using two or more types of substance. The corresponding figure for the comparison group was $19 \%$. Further, $17 \%$ of the street sweepers reported that they were not satisfied with their occupation, and $8 \%$ of the comparison group did so.

The prevalence of MSDs and related disabilities during the previous 12 months in various musculoskeletal sites has been presented in table 2 both for the street sweepers and for the comparison group. The results show that the street sweepers were at a significantly higher risk of developing MSDs compared with the comparison group, specifically for the shoulders (32\%), wrists/hands (29\%), elbows $(27 \%)$ and neck $(17 \%)$. These figures were $11 \%, 19 \%, 9 \%$ and $11 \%$, 
Table 1 Descriptive statistics of the study groups

\begin{tabular}{|c|c|c|}
\hline $\begin{array}{l}\text { Background } \\
\text { characteristics }\end{array}$ & $\begin{array}{l}\text { Street sweeper } \\
\mathrm{N}=180\end{array}$ & $\begin{array}{l}\text { Comparisor } \\
\text { group } \\
\mathrm{N}=180\end{array}$ \\
\hline Workers' age & \multicolumn{2}{|c|}{$(t=-0.952 ; p=0.3416)$} \\
\hline 19-34 years & 45.5 & 34.4 \\
\hline 35 and above & 54.4 & 65.5 \\
\hline Mean age $\pm S D$ & $37.3 \pm 9.1$ & $38.1 \pm 7.4$ \\
\hline Years of working & \multicolumn{2}{|l|}{$(\mathrm{t}=-1.123 ; \mathrm{p}=0.261)$} \\
\hline Below 10 & 67.8 & 51.1 \\
\hline 10 or more & 32.2 & 48.9 \\
\hline Mean \pm SD & $10.6 \pm 8.3$ & $11.4 \pm 6.3$ \\
\hline \multicolumn{3}{|l|}{ Substance use } \\
\hline No addiction & 33.3 & 53.3 \\
\hline Any one & 68.6 & 46.6 \\
\hline Two or more & 32.2 & 19.4 \\
\hline \multicolumn{3}{|c|}{ Mental health (GHQ-12) } \\
\hline Good & 47.2 & 35.6 \\
\hline Intermediate & 21.7 & 28.9 \\
\hline Poor & 31.1 & 35.6 \\
\hline \multicolumn{3}{|l|}{ Job satisfaction } \\
\hline Good & 17.8 & 30.5 \\
\hline Average & 65.0 & 61.1 \\
\hline $\mathrm{Bad}$ & 17.2 & 8.3 \\
\hline \multicolumn{3}{|l|}{ BMI } \\
\hline$<25$ & 65.6 & 51.7 \\
\hline$>25$ & 34.4 & 48.3 \\
\hline Mean $\mathrm{BMI}_{ \pm} \mathrm{SD}$ & $23.6 \pm 1.4$ & $25.1 \pm 3.3$ \\
\hline \multicolumn{3}{|l|}{ Caste } \\
\hline $\mathrm{SC} / \mathrm{ST}$ & 85.6 & 51.7 \\
\hline Others & 14.4 & 48.3 \\
\hline
\end{tabular}

BMI,body mass index; GHQ-12,General Health Questionnaire of 12 items; SC,scheduled caste; ST,scheduled tribe.

respectively, for the comparison group. Similarly, the street sweepers differed significantly from the comparison group in terms of disabilities suffered during the previous 12 months. For instance, the percentage of sweepers who suffered disability due to pain in the lower back, upper back, wrists/hands, shoulders, elbows and hips/thighs was $27 \%, 27 \%, 26 \%, 24 \%, 23 \%$ and $17 \%$, respectively. In the case of the comparison group, the corresponding figures were 18\%, 19\%, $13 \%, 9 \%, 6 \%$ and $8 \%$, respectively. Additionally, the incidence of MSDs during the previous 7 days was significantly higher among the sweepers, particularly for the upper back $(19 \%)$, wrists/hands $(17 \%)$, hips/thighs $(17 \%)$, elbows $(16 \%)$, lower back $(15 \%)$ and shoulders $(11 \%)$ compared with the comparison group (4\%, 3\%, $7 \%, 4 \%, 9 \%$ and $4 \%$, respectively).

\section{Street sweeping augments the MSDs}

In order to assess the effects of sweeping on the development of MSDs, the PSM method was employed. The results have been exhibited in table 3 in terms of the AEEE for MSDs and disabilities during the previous 12 months. The results of the AEEE highlighted that the occupation of sweeping raised the episodes of MSDs, particularly for the shoulders (17\%), wrists/hands (14\%), elbows $(13 \%)$, upper back $(12 \%)$, neck $(10 \%)$ and hips/thighs (9\%). A similar pattern was observed for MSD led disabilities, which were significantly higher for the shoulders (16\%), lower back (14\%), wrists/ hands (14\%), upper back (13\%), elbows (13\%) and hips/thighs (12\%). In a nutshell, the results of the PSM demonstrated that the occupation of sweeping significantly enhanced MSDs and disabilities.

\section{Factors associated with MSDs}

The individual risk factors enhancing MSDs among the sweepers in the previous 12 months were identified after adjusting for the workers' age, body mass index (BMI) and caste. The results for the same have been presented in table 4. The results exhibited that years of working emerged as a significant predictor of development of MSDs. For instance, the sweepers working for 10 or more years were significantly more likely to suffer from MSDs in the elbows $(\mathrm{OR}=10.79 ; \mathrm{p}<0.01)$, shoulders $(\mathrm{OR}=6.40 ; \mathrm{p}<0.01)$, wrists $/$ hands $\quad(\mathrm{OR}=6.08 ; \mathrm{p}<0.01)$, upper back $(\mathrm{OR}=6.06 ; \mathrm{p}<0.01)$, neck $(\mathrm{OR}=5.41 ; \mathrm{p}<0.01)$ and hips/thighs $(\mathrm{OR}=4.49 ; \mathrm{p}<0.01)$ as compared with the sweepers working for $<10$ years. Job satisfaction and MSDs were also found to be significantly correlated as the sweepers who were not satisfied with their job were more likely to have suffered from the MSDs in the wrists/hands $(\mathrm{OR}=11.43 ; \mathrm{p}<0.01)$, hips/thighs $(\mathrm{OR}=5.42$; $\mathrm{p}<0.01)$, upper back $(\mathrm{OR}=4.52 ; \mathrm{p}<0.05)$ and lower back $(\mathrm{OR}=3.91 ; \mathrm{p}<0.05)$ as compared with the sweepers who reported to be satisfied with their jobs.

The location of work too was found to be a significant predictor of developing MSDs. Sweepers working in high slum concentration areas were more likely to get MSDs in the hips/thighs $(\mathrm{OR}=10.64 ; \mathrm{p}<0.01)$, lower back $(\mathrm{OR}=5.22 ; \mathrm{p}<0.01)$ and elbows $(\mathrm{OR}=0.23 ; \mathrm{p}<0.01)$ as compared with those working in the low slum concentration areas.

An inquiry was also made to identify the individual factors enhancing the risk of disabilities during the previous 12 months. The results of the inquiry depicted in table 5-suggested that the number of years of working is significantly correlated with disabilities. More specifically, the sweepers working for 10 and more years were significantly more likely to suffer from disabilities in the elbows (OR=8.12; $\mathrm{p}<0.01)$, hips/ thighs $\quad(\mathrm{OR}=6.27 ; \quad \mathrm{p}<0.01)$, wrists $/$ hands $\quad(\mathrm{OR}=4.98$; $\mathrm{p}<0.01)$, upper back $(\mathrm{OR}=4.40 ; \mathrm{p}<0.01)$ and lower back $(\mathrm{OR}=3.45 ; \mathrm{p}<0.01)$ as compared with those working for $<10$ years. Job satisfaction and mental health were not found to be significantly correlated with disabilities among the sweepers. The sweepers working in the high slum concentration areas were significantly more likely to develop disabilities in the hips/thighs $(\mathrm{OR}=16.17 ; \mathrm{p}<0.01)$, lower back $(\mathrm{OR}=7.79 ; \mathrm{p}<0.01)$, upper back $(\mathrm{OR}=3.20 ; \mathrm{p}<0.01)$ and elbows $(\mathrm{OR}=0.22$; $\mathrm{p}<0.01)$, as compared with the sweepers working in the low slum concentration areas. 
Table 2 Prevalence and incidence of musculoskeletal disorders and disabilities among the study groups in the past 7 days and 12 months

\begin{tabular}{|c|c|c|c|}
\hline Body regions & Street sweeper $\mathrm{N}=\mathbf{1 8 0}$ & $\begin{array}{l}\text { Comparison group } \\
\mathrm{N}=180\end{array}$ & $\chi^{2}$ test \\
\hline \multicolumn{4}{|l|}{ Neck } \\
\hline Past 12 months & $16.7 \%$ & $10.6 \%$ & $\chi^{2}=2.858 ; p=0.091$ \\
\hline Disabled in past 12 months & $10.6 \%$ & $9.4 \%$ & $\chi^{2}=0.123 ; p=0.725$ \\
\hline 7 days & $6.7 \%$ & $4.4 \%$ & $\chi^{2}=0.847 ; p=0.357$ \\
\hline \multicolumn{4}{|l|}{ Shoulders } \\
\hline Past 12 months & $31.7 \%$ & $11.1 \%$ & $\chi^{2}=22.616 ; p=0.000$ \\
\hline Disabled in past 12 months & $24.4 \%$ & $9.4 \%$ & $\chi^{2}=14.388 ; p=0.000$ \\
\hline 7 days & $10.6 \%$ & $4.4 \%$ & $\chi^{2}=4.844 ; p=0.028$ \\
\hline \multicolumn{4}{|l|}{ Elbows } \\
\hline Past 12 months & $26.7 \%$ & $8.9 \%$ & $\chi^{2}=19.459 ; p=0.000$ \\
\hline Disabled in past 12 months & $23.3 \%$ & $5.6 \%$ & $\chi^{2}=23.017 ; p=0.000$ \\
\hline 7 days & $16.1 \%$ & $4.4 \%$ & $\chi^{2}=13.284 ; p=0.000$ \\
\hline \multicolumn{4}{|l|}{ Wrists/hands } \\
\hline Past 12 months & $29.4 \%$ & $18.9 \%$ & $\chi^{2}=5.471 ; p=0.019$ \\
\hline Disabled in past 12 months & $26.1 \%$ & $13.3 \%$ & $\chi^{2}=9.281 ; p=0.002$ \\
\hline 7 days & $16.7 \%$ & $2.8 \%$ & $\chi^{2}=19.780 ; p=0.000$ \\
\hline \multicolumn{4}{|l|}{ Upper back } \\
\hline Past 12 months & $33.9 \%$ & $27.2 \%$ & $\chi^{2}=1.885 ; p=0.170$ \\
\hline Disabled in past 12 months & $26.7 \%$ & $18.9 \%$ & $\chi^{2}=3.095 ; p=0.079$ \\
\hline 7 days & $18.9 \%$ & $3.9 \%$ & $\chi^{2}=20.065 ; p=0.000$ \\
\hline \multicolumn{4}{|l|}{ Lower back } \\
\hline Past 12 months & $33.3 \%$ & $29.4 \%$ & $\chi^{2}=0.632 ; p=0.427$ \\
\hline Disabled in past 12 months & $26.7 \%$ & $17.8 \%$ & $\chi^{2}=4.114 ; p=0.043$ \\
\hline 7 days & $15.6 \%$ & $8.9 \%$ & $\chi^{2}=3.728 ; p=0.053$ \\
\hline \multicolumn{4}{|l|}{ Hips/thighs } \\
\hline Past 12 months & $26.7 \%$ & $20.0 \%$ & $\chi^{2}=2.236 ; p=0.135$ \\
\hline Disabled in past 12 months & $16.7 \%$ & $7.8 \%$ & $\chi^{2}=6.628 ; p=0.010$ \\
\hline 7 days & $17.2 \%$ & $6.7 \%$ & $\chi^{2}=9.534 ; p=0.002$ \\
\hline \multicolumn{4}{|l|}{ Knees } \\
\hline Past 12 months & $1.7 \%$ & $3.9 \%$ & $\chi^{2}=1.6457 ; p=0.200$ \\
\hline Disabled in past 12 months & $0.6 \%$ & $3.3 \%$ & $\chi^{2}=3.6423 ; p=0.056$ \\
\hline 7 days & $1.7 \%$ & $0.6 \%$ & $\chi^{2}=1.0112 ; p=0.315$ \\
\hline \multicolumn{4}{|l|}{ Ankles/feet } \\
\hline Past 12 months & $3.9 \%$ & $2.2 \%$ & $\chi^{2}=0.8440 ; p=0.358$ \\
\hline Disabled in past 12 months & $1.7 \%$ & $2.2 \%$ & $\chi^{2}=0.1457 ; p=0.703$ \\
\hline 7 days & $2.2 \%$ & $0.6 \%$ & $\chi^{2}=1.8254 ; p=0.177$ \\
\hline
\end{tabular}

Table 3 AEEE to the street sweeping occupation on developing MSDs and disabilities for various body regions in the past 12 months

\begin{tabular}{|c|c|c|}
\hline Body regions & $\begin{array}{l}\text { MSDs } \\
\text { Coefficient }(95 \% \mathrm{Cl})\end{array}$ & $\begin{array}{l}\text { Disabilityt due to MSDs } \\
\text { Coefficient }(95 \% \mathrm{Cl})\end{array}$ \\
\hline Neck & $0.10^{* *}(0.02$ to 0.19$)$ & $0.02(-0.05$ to 0.09$)$ \\
\hline Shoulders & $0.17^{\star \star \star}(0.07$ to 0.27$)$ & $0.16^{\star \star \star}(0.07$ to 0.24$)$ \\
\hline Elbows & $0.13^{\star \star \star}(0.05$ to 0.21$)$ & $0.13^{\star \star \star}(0.06$ to 0.19$)$ \\
\hline Wrists/hands & $0.14^{* *}(0.06$ to 0.22$)$ & $0.14^{\star \star \star}(0.07$ to 0.21$)$ \\
\hline Upper back & $0.12^{\star \star \star}(0.04$ to 0.21$)$ & $0.13^{\star * \star}(0.05$ to 0.22$)$ \\
\hline Lower back & $0.08^{*}(-0.02$ to 0.18$)$ & $0.14^{* * *}(0.05$ to 0.23$)$ \\
\hline Hips/thighs & $0.09^{\star *}(0.00$ to 0.18$)$ & $0.12^{* * \star}(0.05$ to 0.18$)$ \\
\hline
\end{tabular}

${ }^{* *} p<0.05,{ }^{* * *} p<0.01,{ }^{*} p<0.1$.

$\dagger$ Prevented normal activity at home or away from home due to MSDs.

AEEE, average exposure effect among exposed; MSD, musculoskeletal disorder. 
Table 4 OR showing individual risk factors for MSDs among street sweepers (past 12 months)

\begin{tabular}{|c|c|c|c|c|c|c|c|}
\hline & Neck & Shoulders & Elbows & Wrists/hands & Upper back & Lower back & Hips/thighs \\
\hline \multicolumn{8}{|c|}{ Years of working } \\
\hline \multicolumn{8}{|c|}{ Below 10 years } \\
\hline 10 and & $5.41^{* \star *}(1.60$ to 18.26$)$ & $6.40^{\star * *}(2.45$ to 16.73$)$ & $10.79^{* * *}(3.49$ to 33.38$)$ & $6.08^{\star * \star}(2.31$ to 15.99$)$ & $6.06^{\star \star *}(2.42$ to 15.19$)$ & $2.96^{\star \star *}(1.23$ to 7.09$)$ & $4.49^{\star \star *}(1.69$ to 11.91$)$ \\
\hline more years & & & & & & & \\
\hline \multirow{2}{*}{\multicolumn{8}{|c|}{$\begin{array}{l}\text { Job satisfaction } \\
\text { High }\end{array}$}} \\
\hline & & & & & & & \\
\hline Medium & $0.53(0.15$ to 1.85$)$ & $2.16(0.74$ to 6.30$)$ & $2.55(0.70$ to 9.26$)$ & $6.41^{* *}(1.32$ to 31.11$)$ & $5.13^{\star * *}(1.49$ to 17.66$)$ & $1.58(0.58$ to 4.26$)$ & $2.58(0.77$ to 8.63$)$ \\
\hline Low & 2.19 (0.55 to 8.63$)$ & 1.89 (0.52 to 6.84$)$ & 2.38 (0.53 to 10.68 ) & $11.43^{\star * \star}(2.04$ to 64.08$)$ & $4.52^{\star *}(1.11$ to 18.42$)$ & $3.91^{\star *}(1.19$ to 12.83$)$ & $5.42^{\star * *}(1.33$ to 21.94$)$ \\
\hline \multicolumn{8}{|c|}{ Mental health } \\
\hline \multicolumn{8}{|l|}{ Low } \\
\hline Medium & $0.22(0.02$ to 2.11$)$ & $0.24^{*}(0.05$ to 1.17$)$ & $0.21^{*}(0.04$ to 1.15$)$ & $0.30^{*}(0.07$ to 1.32$)$ & 0.78 (0.22 to 2.68$)$ & $0.84(0.24$ to 2.88$)$ & $0.31(0.56$ to 1.77$)$ \\
\hline High & $1.15(0.43$ to 3.05$)$ & $1.83(0.81$ to 4.14$)$ & $1.57(0.63$ to 3.87$)$ & $1.30(0.53$ to 3.17$)$ & $1.90^{*}(0.83$ to 4.37$)$ & $1.28(0.56$ to 2.94$)$ & 1.70 (0.68 to 4.22$)$ \\
\hline \multicolumn{8}{|c|}{ Location of work based on proportion of slums } \\
\hline \multicolumn{8}{|c|}{ Low } \\
\hline Moderate & $0.43(0.14$ to 1.32$)$ & $0.93(0.38$ to 2.26$)$ & $0.96(0.38$ to 2.41$)$ & $1.06(0.42$ to 2.68$)$ & $2.04(0.82$ to 5.06$)$ & $2.18^{\star}(0.86$ to 5.51$)$ & $4.12^{\star \star \star}(1.30$ to 13.01$)$ \\
\hline High & $0.40^{*}(0.13$ to 1.16$)$ & 0.77 (0.32 to 1.87$)$ & $0.23^{\star \star \star}(0.08$ to 0.66$)$ & $0.44^{*}(0.16$ to 1.15$)$ & $2.13^{*}(0.86$ to 5.27$)$ & $5.22^{\star \star \star}(2.10$ to 12.95$)$ & $10.64^{\star \star \star}(3.48$ to 32.50$)$ \\
\hline
\end{tabular}

Table 5 OR showing individual risk factors for disabilities due to MSDs among street sweepers (past 12 months)

\begin{tabular}{|c|c|c|c|c|c|c|c|}
\hline & Neck & Shoulders & Elbows & Wrists/hands & Upper back & Lower back & Hips/thighs \\
\hline \multicolumn{8}{|l|}{ Years of working } \\
\hline \multicolumn{8}{|l|}{ Below 10 years } \\
\hline 10 and more years & $6.38^{\star \star}$ (1.16 to 34.91$)$ & $3.13^{\star \star \star}(1.22$ to 8.05$)$ & $8.12^{\star * *}(2.62$ to 25.13$)$ & $4.98^{\star \star \star}(1.86$ to 13.33$)$ & $4.40^{* * *}(1.66$ to 11.62$)$ & $3.45^{\star \star *}(1.33$ to 8.91$)$ & $6.27^{\star \star \star}(2.00$ to 19.60$)$ \\
\hline \multicolumn{8}{|l|}{ Job satisfaction } \\
\hline \multicolumn{8}{|l|}{ High } \\
\hline Medium & $0.28^{*}$ (0.06 to 1.27$)$ & 1.30 (0.44 to 3.82$)$ & 1.85 (0.50 to 6.76$)$ & $4.78^{\star \star}(0.96$ to 23.68$)$ & $3.37^{\star \star}(0.99$ to 11.47$)$ & 1.33 (0.46 to 3.86$)$ & 1.75 (0.46 to 6.59$)$ \\
\hline Low & $1.32(0.26$ to 6.66$)$ & 0.73 (0.18 to 2.90$)$ & $1.98(0.44$ to 8.93$)$ & $7.66^{* *}(1.33$ to 43.87$)$ & 2.93 (0.71 to 12.11$)$ & $4.08^{* \star}(1.16$ to 14.35$)$ & 1.80 (0.37 to 8.62$)$ \\
\hline \multicolumn{8}{|l|}{ Mental health } \\
\hline \multicolumn{8}{|l|}{ Low } \\
\hline Medium & 0.37 (0.35 to 3.86$)$ & 0.18 (0.02 to 1.49$)$ & $0.29(0.05$ to 1.56$)$ & $0.43(0.10$ to 1.87$)$ & $1.12(0.30$ to 4.13$)$ & 0.88 (0.22 to 3.48$)$ & 0.31 (0.03 to 3.00$)$ \\
\hline High & 1.10 (0.32 to 3.72$)$ & 1.85 (0.79 to 4.29$)$ & 1.67 (0.67 to 4.18$)$ & 1.65 (0.67 to 4.08$)$ & $2.77^{\star \star}(1.17$ to 6.55$)$ & 1.05 (0.43 to 2.58$)$ & $1.49(0.53$ to 4.16$)$ \\
\hline \multicolumn{8}{|c|}{ Location of work based on proportion of slums } \\
\hline \multicolumn{8}{|c|}{ Low } \\
\hline Moderate & $0.03^{\star \star \star}(0.00$ to 0.34$)$ & $0.56(0.21$ to 1.44$)$ & $0.93(0.36$ to 2.38$)$ & $0.88(0.34$ to 2.28$)$ & $2.58^{*}(0.95$ to 6.97$)$ & $2.45^{\star}(0.83$ to 7.23$)$ & $7.31^{\star \star \star}(1.39$ to 38.24$)$ \\
\hline High & $0.25^{\star \star}(0.07$ to 0.85$)$ & $0.6(0.25$ to 1.53$)$ & $0.22^{\star \star \star}(0.07$ to 0.65$)$ & $0.37^{\star *}(0.13$ to 1.00$)$ & $3.20^{* \star *}(1.21$ to 8.48$)$ & $7.79^{\star \star \star}(2.76$ to 21.99$)$ & $16.17^{\star \star \star}(3.30$ to 79.22$)$ \\
\hline
\end{tabular}




\section{DISCUSSION}

Sweepers work for long hours in public places using long-handle brooms along with wheelbarrows. This repetitive, rigorous occupation increases the prevalence of MSDs and related disabilities among the street sweepers compared with the comparison group. The results of bivariate analysis showed that the prevalence of MSDs among the street sweepers was significantly higher for the shoulders (32\%), wrists/hands (29\%) and elbows $(27 \%)$ as compared with the comparison group during the previous 12 months. Field observation suggested that this may be because of continuous sweeping with long-handle brooms and carrying collected waste in the wheelbarrows to the community dustbins manually in an unvarying posture. MSDs among street sweepers were also found to be significantly higher for the lower back (27\%), wrists/hands (26\%), shoulders (24\%), elbows (23\%) and hips/thighs $(17 \%)$ as compared with the comparison group over the previous 12 months.

The results of the PSM method revealed that the AEEE to the sweeping occupation significantly enhanced the prevalence of the MSDs for the shoulders (17\%), wrists/hands (14\%), elbows (13\%) and upper back $(12 \%)$. A similar pattern was observed in case of disabilities, particularly for those of the shoulders $(16 \%)$, wrists/hands (14\%), lower back (14\%), elbows (13\%) and upper back (13\%). After adjusting for the age, the BMI and the caste of the street sweepers, the results of the multivariate logistic regression model revealed that years of working, job satisfaction and location of work were significantly correlated with pain in the shoulders, elbows, wrists/hands, lower back, upper back and hips/ thighs.

The location of work emerged as a significant predictor of increased likelihood of MSDs and related disabilities among the street sweepers due to the higher quantum of work in the high slum concentration areas. In the absence of any studies on MSDs among the street sweepers, the results of the present study are comparable with the other studies conducted among the solid waste workers except in the case of knee and ankle disorders. ${ }^{3} 4112728$ This may be because the street sweepers are not engaged in lifting heavy loads continuously or for carrying them for long duration, as a result of which they do not put as much pressure on the knees and ankles as those engaged in solid waste collection. A cross-sectional study conducted in Iran among 217 municipal solid waste workers showed a higher prevalence of the MSDs for lower back (45\%), knees (29\%), shoulders (24\%), upper back (23\%) and neck $(22 \%)$ as compared with the comparison group. ${ }^{5}$ A similar study conducted in India among 313 waste workers concluded that the prevalence of MSDs was higher among the solid waste workers, particularly for the knees $(39 \%)$, lower back $(33 \%)$, shoulders (30\%), elbows $(27 \%)$, ankles $(22 \%)$, wrists $(21 \%)$ and neck $(17 \%) .{ }^{11}$ These findings are in tune with the present study in offering the evidence that workers associated with municipal solid waste management have higher MSDs compared with the general population. The results of the study may be generalised for the street sweepers of India and other developing countries where sweeping is carried out manually.

Past meta-analysis studies have indicated that substance use-such as alcohol consumption, smoking and chewing tobacco-affects the physical capacity for work and causes musculoskeletal pain. ${ }^{29}{ }^{30}$ We observed that 7 out of 10 sweepers were using at least one substance (tobacco, smoking or alcohol) and that around one-third of them were using two or more substances.

The occupational structure in India is influenced by the social structure and the caste system. The scheduled caste (SC) communities, that is, communities which were previously considered untouchable and were economically the weakest were historically assigned cleaning or menial work and were discriminated against. ${ }^{31}$ Today, things have not changed much and it is seen that the majority of the employees working in solid waste management belong to the SCs. The present study shows that more than $86 \%$ of the sweepers belong to the SCs and that only a marginal proportion come from the other caste groups.

\section{Limitations of the study}

In the present study, biases might have occurred due to subjectivity in the response since the severity of MSDs was not quantified. We have adopted the standard tool to assess the self-reported MSDs and validated methods which helped us to avoid biases. Moreover, the chances of misreporting are low as the study guaranteed confidentiality and assurance. The cross-sectional survey method used for data collection may have underestimated or overestimated the actual prevalence of MSDs and related disabilities due to a year long reference period, which may have led to recall bias. Additionally, the cross-sectional study design has a limitation of conducting survey at one time point and therefore it gives no indication of the sequence of events. ${ }^{32}$ There may also be seasonal variations in the prevalence rate of MSDs among sweepers. For instance, the prevalence of MSDs may increase during the rainy season because of the waste getting wet and therefore requiring extra energy for sweeping than in the other seasons. Previous studies have revealed a significant relationship between seasonal variations in the work environment and the health risk posed to the workers associated with waste collection. ${ }^{33}$ Since the survey for the present study was carried out at a specific point in time, seasonal variations in the prevalence of MSDs were not covered. This study was conducted among municipal street sweepers sweeping public places; the results may be generalised with caution.

Past studies have demonstrated that job rotation between waste collectors, street sweepers and drivers helps to reduce the workload as well as the risk of 
MSDs. ${ }^{34}$ Sweepers sweeping in high slum concentration areas may be shifted to low slum concentration areas since the workload varies by place of work. Job rotation and change in the place of work may reduce the risk of MSDs and related disabilities. The burden of disabilities may be reduced by taking curative measures at an early stage and by providing proper treatment.

Acknowledgements The authors acknowledge the English editing services of Shailja Thakur.

Contributors PSS contributed to the conceptualisation, design and data analysis. PC led the conceptualisation, data analysis and writing. Both the authors have read and approved the final manuscript.

Funding This research work received no specific grant from any funding agency in the public, commercial or not-for-profit sector.

Competing interests None declared.

Ethics approval The study was approved by the Student Research Ethics Committee of the International Institute for Population Sciences, Mumbai.

Provenance and peer review Not commissioned; externally peer reviewed.

Data sharing statement No additional data are available.

Open Access This is an Open Access article distributed in accordance with the Creative Commons Attribution Non Commercial (CC BY-NC 4.0) license, which permits others to distribute, remix, adapt, build upon this work noncommercially, and license their derivative works on different terms, provided the original work is properly cited and the use is non-commercial. See: http:// creativecommons.org/licenses/by-nc/4.0/

\section{REFERENCES}

1. Anwar SK, Mehmood N, Nasim N, et al. Sweeper's lung disease: a cross-sectional study of an overlooked illness among sweepers of Pakistan. Int J Chronic Obstr Pulm Dis 2013;8:193-7.

2. Nku CO, Peters EJ, Eshiet Al, et al. Lung function, oxygen saturation and symptoms among street sweepers in Calabar-Nigeria Niger J Physiol Sci 2005;20:79-84.

3. Nagaraj C, Shivaram C, Kumar JK, et al. A study of morbidity and mortality profile of sweepers working under Bangalore City Corporation. Indian J Occup Environ Med 2004;8:11-18.

4. Sabde YD, Zodpey SP. A study of morbidity pattern in street sweepers: a cross-sectional study. Indian J Community Med 2008;33:224-8.

5. Mehrdad R, Majlessi-Nasr M, Aminian O, et al. Musculoskeletal disorders among municipal solid waste workers. Acta Med Iran 2008;46:233-8.

6. Abou-EIWafa HS, El-Bestar SF, El-Gilany AH, et al. Musculoskeletal disorders among municipal solid waste collectors in Mansoura Egypt: a cross-sectional study. BMJ Open 2012;2:e001338.

7. Dorevitch S, Marder D. Occupational hazards of municipal solid waste workers. Occup Med Philadelphia Pa 2001;16:125-33.

8. Keyserling WM. Workplace risk factors and occupational musculoskeletal disorders, part 1: a review of biomechanical and psychophysical research on risk factors associated with low-back pain. AIHAJ 2000;61:39-50.

9. Hoozemans MJM, Kuijer PPFM, Kingma I, et al. Mechanical loading of the low back and shoulders during pushing and pulling activities. Ergonomics 2004;47:1-18.

10. IJzelenberg W, Molenaar D, Burdorf A. Different risk factors for musculoskeletal complaints and musculoskeletal sickness absence. Scand J Work Environ Health 2004;30:56-63.
11. Jayakrishnan $T$, Jeeja M, Bhaskar R. Occupational health problems of municipal solid waste management workers in India. Int J Environ Health Eng 2013;2:42.

12. Johncy SS, G D, Samuel TV, et al. Acute lung function response to dust in street sweepers. J Clin Diagn Res 2013;7:2126-9.

13. Yogesh SD, Zodpey SP. Respiratory morbidity among street sweepers working at Hanumannagar Zone of Nagpur Municipal Corporation, Maharashtra. Indian J Public Health 2008;52:147-9.

14. Johncy SS, Dhanyakumar G, Kanyakumari, et al Chronic exposure to dust and lung function impairment: a study on female sweepers in India. Natl J Physiol Pharm Pharmacol 2014;4:15-19.

15. Kuorinka I, Jonsson B, Kilbom A, et al. Standardised Nordic questionnaires for the analysis of musculoskeletal symptoms. Appl Ergon 1987; 18:233-7.

16. Moreira-Silva I, Santos R, Abreu S, et al. Associations between body mass index and musculoskeletal pain and related symptoms in different body regions among workers. SAGE Open 2013;3:1-6.

17. Viester L, Verhagen EA, Oude Hengel KM, et al. The relation between body mass index and musculoskeletal symptoms in the working population. BMC Musculoskelet Disord 2013;14:238.

18. Linton SJ. A review of psychological risk factors in back and neck pain. Spine 2000;25:1148-56.

19. Macfarlane GJ, Hunt IM, Silman AJ. Role of mechanical and psychosocial factors in the onset of forearm pain: prospective population based study. BMJ 2000;321:676-9.

20. Bongers PM, de Winter CR, Kompier MA, et al. Psychosocial factors at work and musculoskeletal disease. Scand J Work Environ Health 1993;19:297-312.

21. Madan I, Reading I, Palmer KT, et al. Cultural differences in musculoskeletal symptoms and disability. Int $J$ Epidemiol 2008;37:1181-9.

22. Solidaki E, Chatzi L, Bitsios $\mathrm{P}$, et al. Work-related and psychological determinants of multisite musculoskeletal pain. Scand J Work Environ Health 2010;36:54-61.

23. Montazeri A, Harirchi AM, Shariati M, et al. The 12-item General Health Questionnaire (GHQ-12): translation and validation study of the Iranian version. Health Qual Life Outcomes Bio Med Cent 2003;1:66

24. Ram U, Strohschein L, Gaur K. Gender socialization: differences between male and female youth in India and associations with mental health. Int J Popul Res 2014;2014:1-11.

25. Rosenbaum PR, Rubin DB. The central role of the propensity score in observational studies for causal effects. Biometrika 1983;70:41-55.

26. Rubin DB, Thomas N, Rubin DB. Matching using estimated propensity scores: relating theory to practice. Biometrics 1996;52:249-64.

27. Norman ID, Kretchy JP, Brandford E. Neck, wrist and back pain among solid waste collectors: case study of a Ghanaian waste management company. Open Public Health J 2013;6:59-66.

28. Singh S, Chokhandre P. Assessing the impact of waste picking on musculoskeletal disorders among waste pickers in Mumbai, India: a cross-sectional study. BMJ Open 2015;5:e008474.

29. Phonrat $B$, Pongpaew $P$, Tungtrongchitr R, et al. Risk factors for chronic diseases among road sweepers in Bangkok. Southeast Asian J Trop Med Public Health 1997;28:36-45.

30. Ueno S, Hisanaga $\mathrm{N}$, Jonai $\mathrm{H}$, et al. Association between musculoskeletal pain in Japanese construction workers and job, age, alcohol consumption, and smoking. Ind Health 1999;37:449-56.

31. Deshpande A. The grammar of caste: economic discrimination in contemporary India. Oxford University Press, 2011.

32. Levin KA. Study design III: cross-sectional studies. Evid Based Dent 2006;7:24-5.

33. Ivens UI, Ebbehøj N, Poulsen OM, et al. Season, equipment, and job function related to gastrointestinal problems in waste collectors. Occup Environ Med 1997;54:861-7.

34. Kuijer PP, Visser B, Kemper HC. Job rotation as a factor in reducing physical workload at a refuse collecting department. Ergonomics 1999;42:1167-78. 